\title{
Políticas habitacionales y urbanismo neoliberal: la intervención estatal en la Villa 20, Argentina (1984-2018)
}

Housing policies and neoliberal urbanism: State intervention in Villa 20, Argentina (1984-2018)

\section{Mariela Diaz*}

Recibido: 07 de diciembre de 2018

Aceptado: 30 de abril de 2019

\section{Resumen}

El objetivo de este trabajo es explorar las políticas habitacionales en la Villa 20 de la Ciudad Autónoma de Buenos Aires (CABA), Argentina, en el periodo neoliberal 1984-2018. Específicamente, se analiza el rol de la intervención estatal de manera longitudinal y su relación con el hábitat popular informal y sus organizaciones barriales, con especial hincapié en la normativa y la regulación urbana, incluyendo antecedentes como la actual Ley №5705/2016 de "Reurbanización, Zonificación e integración sociourbana de la Villa 20". Se problematiza la relación entre la política habitacional y sus efectos en la trama socio urbana levantando como interrogante ¿Qué tipo de políticas habitacionales generaron integración o, por el contrario, reforzaron la segregación residencial? Se adoptó una estrategia metodológica multi-método, incorporando datos de fuentes primarias y secundarias, incluyendo datos censales, entrevistas semiestructuradas a informantes clave y una observación no participante. Como principal hallazgo, se plantea que, si bien desde la apertura democrática nacional hubo avances en el plano legal, no se tradujeron en una mejora habitacional concreta de las Villas de la ciudad; expresando un desacople entre la ley y su ejecución.

Palabras clave: hábitat popular, políticas habitacionales, segregación residencial, Villa 20.

\begin{abstract}
The objective of this work is to analyze the housing policies in Villa 20 of the city of Buenos Aires, Argentina, for the neoliberal period 19842018. Specifically, an analysis of the state intervention' role in a longitudinal manner and its relationship with the informal popular habitat and its neighborhood organizations is done, emphasizing in briefs and urban regulations. This analysis includes a key normative background such as the current Law № 5705/2016 of "Redevelopment, Zoning and socio-urban integration of Villa 20". The relationship between housing policy and its effects on the socio-urban grid is problematized by using the question: What type of housing policies generated integration or, on the contrary, reinforced residential segregation? A methodological multi-method strategy was adopted, incorporating data from primary and secondary sources, including census data, semi-structured interviews with key informants as well as non-participant observation. the law and its execution. As a main finding, it is suggested that although the national democratic opening made progress in legal terms, they did not applied to a concrete housing improvement of the 'Villas', which is showing a lack of relationship between the law and its enforcement.
\end{abstract}

Keywords: housing policies, popular habitat, residential segregation, Villa 20.

\footnotetext{
* Filiación: CONICET - Universidad de Buenos Aires, Buenos Aires, Argentina. Contacto: madidip@gmail.com
}

Este artículo contó con financiamiento del Consejo Nacional de Investigaciones Científicas y Técnicas (CONICET, Argentina). 


\section{Introducción}

El surgimiento de las villas en la CABA estuvo ligado a la implantación del modelo de sustitución de importaciones y la crisis del modelo agroexportador hacia la década de 1930. Se consolidaron como lugar alternativo para aquellos sectores, en un primer lugar, migrantes internos y, con posterioridad migrantes limítrofes, que no podían costearse el valor de una pieza de alquiler (Cuenya, 1993; Di Virgilio, Arqueros Mejica y Guevara, 2010; Torres, 2006). En general, los sectores populares ocuparon parcelas fiscales (por ejemplo, terrenos ferroviarios, portuarios) o terrenos privados desocupados con un trazado irregular que contrasta con el damero propio de la ciudad formal. Además, se localizaron en áreas con una cierta accesibilidad al centro y a las fuentes laborales como también en el sur de la ciudad, próximo al Riachuelo (como es el caso de la Villa 20 en el barrio de Villa Lugano) bajo condiciones de pésima habitabilidad (falta de agua y cloacas, edificaciones precarias, hacinamiento, etc.).

El barrio de Villa lugano, perteneciente a la Comuna $8^{1}$, contiene cuatro villas de las veintitrés existentes en la ciudad. Según el Censo de 2010, la Villa 20 es la cuarta más poblada y junto con la Villa 15 (también en el barrio de Lugano) concentran la mitad de la población en villas de la zona sur (Cosacov et al., 2011).

El objetivo de este trabajo es analizar las políticas habitacionales que el Estado impulsó en la Villa 20 y sus efectos en la trama sociourbana desde la apertura democrática en Argentina (1984) hasta el año 2018. Se pretende analizar el rol de la intervención estatal bajo el periodo neoliberal -representante de un capitalismo latinoamericano dependiente- de manera longitudinal y su relación con el hábitat popular -con características segregatorias - y sus organizaciones, con especial énfasis en la normativa y regulación urbana. Esto último con la finalidad de comprender las continuidades y/o rupturas presente en la actual Ley $\mathrm{N}^{\circ} 5705$ (2016) de

\footnotetext{
${ }^{1}$ La CABA se divide en 15 comunas (Ley $\mathrm{N}^{\circ} 1770 / 2005$ ), compuestas por un conjunto de barrios. Se definen como unidades de gestión política y administrativa descentralizada.
}

Reurbanización, Zonificación e Integración Sociourbana de la Villa 20, de ejecución reciente.

Este estudio se inserta en un campo académico con una vasta bibliografía producida sobre la relación entre el plano normativo de las políticas habitacionales en el sur de la CABA y sus consecuencias concretas en el hábitat popular informal. Por consiguiente, este artículo se propone retomar los antecedentes sobre la temática, pero desde una óptica distinta que problematice la relación entre las políticas habitacionales y la injerencia (o no) de las organizaciones barriales; y, a su vez, sus consecuencias en la trama sociourbana. Es decir, indagar sobre el papel que cumple la intervención estatal en la mitigación (o no) de la segregación residencial, así como en el aumento (o no) de la integración sociourbana. Al mismo tiempo, se pretende actualizar el debate a partir de la descripción y análisis de la reciente política de reurbanización que cuenta con escasas investigaciones debido a su reciente sanción (Ley $N^{\circ} 5705,2016$ ).

Cabe preguntarse: ¿Qué tipo de políticas habitacionales generaron integración o por el contrario reforzaron la segregación residencial? ¿Qué vínculos a lo largo de la historia estableció el Estado con las condiciones habitacionales de los sectores populares? ¿Qué efectos tuvieron las demandas históricas de las organizaciones "villeras" en las políticas habitacionales desarrolladas en el periodo propuesto?

En esta dirección, la hipótesis principal de este trabajo es la siguiente: Las normativas analizadas para el caso de la Villa 20 expresan la relación de fuerza entre el Estado y la sociedad civil en un contexto político y económico neoliberal. La existencia de normativas donde las organizaciones barriales pudieron imprimir su sello es una señal de esta afirmación. Pese a esto, se genera un desacople entre la ley y su ejecución, infiriéndose una baja sintonía entre las demandas y las necesidades de la población residente en villas y la respuesta que otorga el Estado bajo el urbanismo neoliberal. Se produce, entonces, la paradoja entre un desarrollo de la dimensión formal/legal y, simultáneamente, un aumento de la desigualdad social y de la segregación residencial del hábitat popular. 


\section{Antecedentes teóricos}

La presencia de las llamadas villas en Argentina, las favelas en Brasil, los campamentos en Chile, así como el hipergueto en los EEUU y las chabolas en España, plantean el problema de la precariedad e informalidad urbana de las sociedades capitalistas (Angelcos y Pérez, 2017; Davis, 2006; Torres Gutiérrez, 2011; Torres Ribeiro, 2004; Wacquant, 2007).

Como señaló Topalov (1979), se encuentra una dificultad para proveer de vivienda a toda la población a través de la producción capitalista (formal) de vivienda, pero como remarcaron los teóricos de la dependencia (Jaramillo, 2012; Jaramillo y Cuervo, 1993), las urbes periféricas presentan una mayor criticidad en relación a los países centrales. Un estudio de Mike Davis (2006, p.23), reveló que los porcentajes más altos de informalidad urbana se concentran en las ciudades capitales de algunos de los países de África, Asia y América Latina.

La informalidad urbana según Clichevsky (2003), comprende dos formas de transgresión: respecto a los aspectos de dominio que se basa en la falta de títulos de propiedad (o contratos de alquiler); y en relación con el proceso de urbanización en cuanto al incumplimiento de las normas de construcción de la ciudad. Desde esta última perspectiva se encuentran las tierras sin condiciones urbano-ambientales para ser usadas como residenciales, es decir: sin infraestructura $y / o$ equipamientos colectivos, con dificultad en el acceso al transporte público o a los centros de empleo, entre otros problemas.

Este artículo propone analizar la informalidad urbana bajo la primera "transgresión" (de dominio de la propiedad o "dominial"), y la segunda transgresión como precariedad de la vivienda y de los componentes colectivos del hábitat que puede caracterizar tanto a la construcción del espacio urbano formal como informal. El estudio de la informalidad urbana y de la precariedad del hábitat puede convertirse (aunque no necesariamente) en un indicador de segregación residencial de la población que habita en un territorio determinado. Las condiciones del hábitat popular pueden caracterizarse, entonces, por diversas vinculaciones entre la informalidad y la precariedad.
El fenómeno de la segregación residencial, que se contrapone a la imagen de una ciudad integrada (en el plano socioeconómico y urbano) es uno de los rasgos distintivos de las urbanizaciones latinoamericanas. Esta noción permite abordar las características del hábitat popular y la configuración territorial de la ciudad respecto a la distribución y al acceso equitativo (o no) a los bienes, servicios, equipamientos e infraestructura.

Como señaló Rodríguez (2014) este concepto carece de una definición precisa, pese a ser objeto de estudio desde hace más de un siglo, primero en los países centrales (EEUU y Europa) y luego en América Latina (desde la década de los años 90). Primero, se presenta una definición clásica/geográfica de la segregación, asociada a la Escuela Ecológica de Chicago (Siglo XX) y vigente en la actualidad, definida como la constatación empírica de que ciertos grupos sociales de similares características tienden agruparse en el espacio. Esto último da cuenta de una división social del espacio (Duahau, 2013; Schteingart, 2001).

Este concepto implica una relación social, ya que es definida como el grado en el que dos o más grupos viven separados uno del otro en diferentes partes del ambiente urbano (Castells, 1974²; Massey y Denton, 1988). Se considera que esta definición operativa posee una utilidad metodológica cuando la investigación se plantea medir u operacionalizar el término segregación. Por este motivo, desde esta perspectiva, la segregación residencial conlleva un contexto de homogeneidad espacial/urbana (configurando un tipo de hábitat) y de relativa ${ }^{3}$ homogeneidad socioeconómica y/o cultural.

2 Castells incluye la noción de jerarquía y de estratificación, introduciendo una relación entre la segregación residencial, las relaciones de poder y la desigualdad social. En esta misma dirección, Park (1926), uno de los exponentes de la primera Escuela de Chicago, señaló que las distancias físicas son indicadores de las distancias sociales. Se desprende entonces la necesidad de explorar la heterogeneidad de visiones dentro de dicha Escuela.

${ }^{3}$ La noción de relativa se debe a la posibilidad de encontrar una desigualdad interna, según pertenencia de clase, migratoria y étnica de la población. Tampoco es asimilable a un gueto debido a las interacciones posibles con el resto de la ciudad, configurándose un amplio abanico de relaciones de subordinación (Wacquant, 2007; Diaz, 2014). 
Lo estudios latinoamericanos se focalizaron en la dimensión económica del proceso de segregación residencial (Adaszko, 2013; Groisman y Suárez, 2006, 2010; Rodríguez, 2008; Zimmermann, 2014)4. En cambio, aquí se considera crucial analizar la estructura de clase y étnica de manera conjunta y no dicotómica. Siguiendo a Quijano (2000), la idea de "raza" es un elemento de colonialidad presente en la estratificación social de América Latina que explica la emergencia de una división étnica o "racial" del trabajo en el marco del capitalismo mundial actual. Esto último permite indagar la relación entre la segregación residencial y las características económicas y socioculturales de la población, no sólo en los países andinos que cuentan con una mayoría indígena, sino en los países del cono sur que han recibido población migrante de los países limítrofes (Clichevsky, 2000).

Asimismo, esta noción no es sólo un dato empírico geográfico sino una relación social de poder, donde se encuentran los segregados y los que segregan (Rodríguez, 2014). En otras palabras, el análisis de la segregación residencial involucra un estudio sobre las condiciones estructurales que la provoca, y sobre los agentes sociales que la promueve (Duhau, 2013). La segregación residencial (y la división social de espacio) puede ser producida a través de los agentes del mercado inmobiliario (formal o informal) o por las políticas del Estado mediante los planes de vivienda y la normativa urbana (Angelcos y Pérez Ahumada, 2017; Clichevsky, 2000; Duhau, 2013; Hidalgo, 2017; Sabatini y Brain, 2008; Schteingart, 2001; Zapata, 2017).

Cabe señalar que los estudios sobre las políticas públicas se centraron, desde una mirada unidireccional, en los impactos producidos por el Estado en materia de integración urbana. Aquí, se intentará descosificar el concepto de Estado ya que es definido como una relación social, correlación de fuerzas y relación de dominación (García Linera, 2011; Rodríguez, 2005) que genera modalidades específicas de resolución del problema de la vivienda y el hábitat (a través de políticas, normativas, programas, planes y proyectos). Es decir, el contenido del derecho a la vivienda/ciudad es el eje de la disputa que

${ }^{4}$ Mientras las producciones de los EEUU y Europa se centraron en la dimensión racial o étnica de la segregación. subyace a toda construcción de la cuestión (problematización social de una necesidad) ${ }^{5}$ y al tipo de resolución propuesta (Oszlak y O’ Donnell, 1981). Por ende, la legislación o la normativa urbana expresa esta correlación de fuerza y esta disputa donde se contrapone segregación residencial e integración sociourbana.

Retomando la concepción de Yujnovsky (1984), el derecho a la vivienda implica el derecho a un hábitat adecuado, el derecho a la ciudad. Esta definición posee dos acepciones. Una definición más inmediata que hace referencia al ejercicio de una ciudadanía plena, la cual integra múltiples derechos, tales como el derecho a la educación, a un empleo adecuado, a la salud pública y a los servicios urbanos, entre otros (Borja, 2011; Suárez, et al., 2009). Y, para una concepción anclada en la posibilidad de un cambio social, este derecho involucra una apropiación positiva del territorio como valor de uso, una reapropiación mediante un control democrático y colectivo de los procesos de urbanización y de la relación con la naturaleza (Harvey, 2012; Lefebvre, 1978).

En esta dirección, la interacción o relación de fuerza entre el Estado y la sociedad civil apunta a decidir cómo se distribuyen la gestión de lo público, los recursos del poder y el excedente social. Es decir, "de qué debe ocuparse el Estado; cuánto le cuesta a quién, y, por último, quién decide de qué hay que ocuparse, quién gana y quién pierde" respectivamente (Oszlak, 2007, p. 3).

El estado neoliberal o la globalización neoliberal tiene su correlato en la construcción de una ciudad neoliberal y es analizada como una nueva fase de la mundialización del capitalismo (Amín, 2003; Pradilla Cobos, 2010). En Latinoamérica comenzó su proceso de consolidación con el ascenso de las dictaduras militares. A partir de las distintas modalidades de resolución de la problemática del hábitat, el Estado se ubicó en una función subsidiaria, promotora, acondicionadora y/o generadora de las condiciones de valorización del territorio (De Mattos,

\footnotetext{
${ }^{5}$ La cuestión puede ser iniciada por el Estado o por la sociedad civil. Cuando el Estado la convierte en agenda pública, la implementación de la política suele generar repercusiones horizontales y verticales al interior de la burocracia estatal, provocando una falta de homogeneidad y coherencia interna.
} 
2002), convirtiéndose en garante de la acumulación por desposesión (Harvey, 2004), en tanto negación del derecho a la ciudad para los sectores populares. De este modo, se encuentran estudios -citados anteriormente-, que analizaron cómo el Estado, incluso a partir de la regulación normativa, produjo segregación residencial en las áreas periféricas de muchas ciudades latinoamericanas, relegando a los sectores populares a un hábitat precario e informal.

Específicamente, las políticas urbanas de la última dictadura militar argentina (1976-1983) se orientaron a la construcción de una ciudad que hay que merecer, ubicando a la ganancia y al capital privado en el centro de la planificación urbana. Durante el año 1970, la intervención del Estado se dirigió a la construcción de una ciudad neoliberal mediante la aplicación de un conjunto de sanciones normativas. Por ejemplo, la ejecución del Plan de Erradicación de Villas -según la Ordenanza №33.652/19776- implicó un intento autoritario de regular el acceso al derecho a la ciudad (Oszlak, 1991; Torres, 2006). Por consiguiente, mediante el estudio de las políticas habitacionales en una Villa de la CABA se tiene la intención de analizar la forma adoptada por el neoliberalismo realmente existente (Brenner y Theodore, 2002) en un país latinoamericano, en tanto se presentan tensiones y contradicciones entre la teoría neoliberal y la pragmática de la neoliberalización (Harvey, 2007).

\section{Metodología}

Para llevar a cabo esta investigación se adoptó una estrategia metodológica multi-método, que combina procedimientos cualitativos y cuantitativos e incorpora datos de fuentes primarias y secundarias.

A continuación, se presenta el proceso de investigación o sus etapas típicas ya que en realidad:

(...) la teoría y la investigación han de interrelacionarse. Toda teoría ha de basarse en hallazgos empíricos para no quedar en una mera especulación ideológica. De igual manera, toda investigación debe partir de una teoría para

${ }^{6}$ La Comisión Municipal de la Vivienda (CMV) bajo la última dictadura militar expulsó el 89,62\% de la población villera de la CABA (Arqueros Mejica, 2016b; Cuenya, 1993; Vitale, 2009). adquirir una mayor relevancia. (Cea D'Ancona, 1999, p. 74)

En primer lugar, se realizó una amplia revisión bibliográfica y un análisis legislativo (de las leyes, de las versiones taquigráficas de las Audiencias Públicas (2016), de los decretos y del Código de Planeamiento Urbano) de manera longitudinal en el tiempo propuesto con el fin de reconstruir los antecedentes sobre el tema y, a su vez, detectar el paradigma interpretativo subyacente. De este modo, de esta reconstrucción, se desprendió la hipótesis de investigación que en un proceso de investigación académico posee un diálogo permanente y dialéctico (o de ida y vuelta) con el territorio bajo análisis.

Se llevó a cabo un trabajo de campo que incluyó una observación no participante en la Villa 20 y sus alrededores, a partir de las visitas guiadas realizadas junto con el IVC7 por un lado, y con un referente de la Villa 20 en el marco de una cátedra de la Facultad de Arquitectura, Diseño y Urbanismo (FADU) de la Universidad de Buenos Aires (UBA) en el área de estudio.

Este trabajo de campo permitió ajustar la hipótesis y generó nuevas preguntas de investigación. Por este motivo, se utilizó el último Censo Nacional de Población, Hogares y Vivienda de la Argentina (INDEC, 2010), que fue analizado mediante el uso del REDATAM. Además, se accedió al informe realizado por el Instituto de la Vivienda de la Ciudad de Buenos Aires (IVC) donde se plasman los datos del Censo aplicado por este organismo en la Villa 20 en el año 2016. Este análisis de índole cuantitativo permitió caracterizar las condiciones sociourbanas, sociodemográficas y económicas de la población residente. Luego, se compararon los avances enunciados por las políticas habitacionales en el plano legal formal y los resultados concretos medidos a través de los datos censales y mediante la observación (no participante) desarrollada en el territorio.

Adicionalmente se efectuaron entrevistas semiestructuradas en profundidad a informantes clave, tales como a referentes del IVC y de la Villa 20 con el fin

\footnotetext{
${ }^{7}$ Con el IVC se realizaron dos recorridos en la Villa 20. El primero, como miembro del Workshop Internacional ¿Urban Voids? Buenos AiresHamburg organizado por la HafenCity University Hamburg y el Centro Estudios del Hábitat y la Vivienda de la FADU (UBA).
} 
de indagar el escenario previo y posterior a la sanción de la Ley de 2016. Esto último se torna necesario ya que se presenta escasa bibliografía sobre la reciente Ley (2016) sancionada. Por consiguiente, se pretendió actualizar la información disponible y aportar nuevos elementos de reflexión.

\section{Situación sociourbana}

Las tierras que se conocen como Villa 20 comenzaron a ocuparse de manera informal en el año 1948 en torno a las viviendas construidas por la Fundación Eva Perón para las familias en hogares de tránsito sobre las calles Larraya y Strangford (Cosacov et al, 2011). El área donde se emplaza la Villa 20 era periférica y con baja consolidación urbana. Sus terrenos eran inundables y su proximidad a la Quema del bajo Flores, donde se depositaban el 70\% de la basura de la ciudad, definían condiciones socioambientales perjudiciales para la localización de las familias.

Actualmente, la Villa 20 ocupa 48 hectáreas, y se encuentra dividida en tres sectores: un sector denominado "consolidado"(36 ha), donde se aplicaron un conjunto de proyectos de reordenamiento hasta mediados de los años 2000; un sector nombrado como "macizo", conformado principalmente a partir de la autoconstrucción y la producción social del hábitat; y, finalmente, un sector actualmente denominado barrio Papa Francisco (12 ha) que se constituyó como un depósito de autos abandonados de la Policía Federal donde actualmente se están construyendo las nuevas viviendas en el marco de la Ley de Reurbanización (Motta y Almansi, 2017).

\section{Indicadores de homogeneidad urbana y socioeconómica relativa}

En esta Villa viven 27.990 personas, representando un aumento del 118\% respecto al año 2001 (Informe del Censo del IVC, 2016), y se configura como la cuarta Villa más poblada de la ciudad. Además, su población es joven: el promedio de edad es de 25 años, dinámica demográfica que la ubica por debajo del promedio de edad del conjunto de la CABA (39 años según el Censo de 2010).

Por su parte, el $42 \%$ del total de los jefes/as de hogar son oriundos de Bolivia, porcentaje que supera a los nacidos en la Argentina (33,5\%) y en otros países limítrofes (el 23\% provienen del Paraguay y el 1,3\% del Perú). La Villa 20 está inmersa en una Comuna que ocupa el segundo lugar con mayor porcentaje de población extranjera (23,3\%) luego de la Comuna 1 (24,8\%), donde se destaca la población de origen boliviana (Sassone y Matossian, 2014). A diferencia del contexto de surgimiento de las villas, el neoliberalismo latinoamericano trajo consigo dos procesos simultáneos: en Bolivia al mismo tiempo que ocurrió una migración rural-urbana, se acentuó la migración internacional, configurándose Buenos Aires en un centro de atracción.

Según el Informe del Censo del IVC (2016), en la Villa 20 se concentran los trabajadores ocupados en empleos informales, precarios $\mathrm{y} / \mathrm{o}$ inestables con salarios por debajo de la media de la CABA, además de la población trabajadora desocupada, con una fuerte presencia del desempleo estructural8. Esto da cuenta de la desigualdad interna y del empobrecimiento de ciertos segmentos dentro de la clase trabajadora.

Recuperando la definición operativa de la segregación residencial, se presentan los siguientes indicadores de precariedad de las condiciones habitacionales de la Villa 20, que expresan a su vez la vulnerabilidad de la Comuna. 8 (Tabla1).

\footnotetext{
8 Las categorías ocupacionales predominantes son las siguientes: obrero/empleado del sector público o privado (43.6\%), cuenta propia (10.8\%) y los que realizan changas $(18.4 \%)$, donde se presentan altos niveles de informalidad y precariedad laboral. Estas categorías ocupacionales representan desiguales ingresos asociados a la presencia o no de la estabilidad laboral según el caso. Asimismo, del total de la población que no trabaja (el $41 \%$ de la población de 14 años y más), existe un $19 \%$ que no encuentra empleo, indicador de desempleo estructural.
} 


\section{Tabla 1}

Indicadores de condiciones habitacionales. Total de hogares de la Villa 20, Comuna 8 y Ciudad de Buenos Aires (CABA). En porcentaje. 2010 y 2016

\begin{tabular}{lccc}
\hline Condiciones habitacionales & Villa 20* & Comuna 8 & CABA \\
\hline Hogares sin agua de red & 4.5 & 0.9 & 0.4 \\
Hogares sin cloacas & 1.6 & 4.6 & 0.9 \\
Hogares sin gas de red & 92.2 & 36.4 & 7.8 \\
Hogares sin red eléctrica & 14 & - & - \\
Insuficiente calidad constructiva & 44.6 & 10.9 & 3.4 \\
\hline
\end{tabular}

Fuente: Censo Nacional de Población, Hogares y Vivienda, 2010 y el Informe del Censo 2016. *Los datos de la Villa 20 refieren al Censo realizado por el IVC en el año 2016

En primer lugar, se destaca el acceso, mediante conexiones informales, a los servicios básicos e infraestructura urbana de una calidad insuficiente, cuestión que provoca la inundación de ciertas zonas de la Villa. Si bien el $98.4 \%$ de las viviendas desagota o converge en una red cloacal, las mismas se encuentran conectadas a la red pluvial, generando un colapso del sistema. Respecto a la provisión del agua se presenta una escasa presión en diversas manzanas de la villa, además de interrupciones reiteradas (Asesoría Tutelar, 2014; IVC, 2016).

El $86 \%$ de las viviendas están conectadas informalmente a la red eléctrica, su precariedad se vincula con la existencia de postes pegados a los hogares y de transformadores cercanos a los domicilios. Por este motivo, durante el año 2013, se sucedieron números incendios con consecuencias fatales originados por estos motivos y también por el uso predominante de la garrafa (Entrevista a un referente barrial). Esta situación de informalidad y precariedad urbana absoluta se integra en un contexto urbano ambiental vulnerable. En las sucesivas visitas realizadas se observó la concentración de residuos debido al deficiente funcionamiento del servicio de recolección de residuos.

Cabe mencionar que la situación de segregación residencial de la población de la Villa 20 se encuentra reforzada por las características de su hábitat y del entorno inmediato. El tejido urbano residencial destinado a una ocupación media que caracteriza a la Comuna según el CPU se destaca por su discontinuidad debido a la presencia de las llamadas barreras urbanas que generan una situación de fragmentación territorial (Figura 1). Esta fragmentación está dada por la existencia de grandes equipamientos e infraestructuras urbanas. Las barreras urbanas que rodean a la Villa 20 son las siguientes: el Parque de la Ciudad, el de las Victorias, el Roca y el Indoamericano; la infraestructura del Metrobús Sur (inaugurada en el año 2013), el premetro, las vías del ferrocarril Belgrano Sur, el hipermercado Jumbo (desde 1983), entre otras. Este hábitat fragmentado que rodea a la Villa 20, genera una carencia de urbanidad. De esta manera, esta situación provoca dificultades en el objetivo de integración sociourbana de la villa con el resto de la ciudad, presente en la política estatal desde el retorno de la democracia hasta la actualidad.

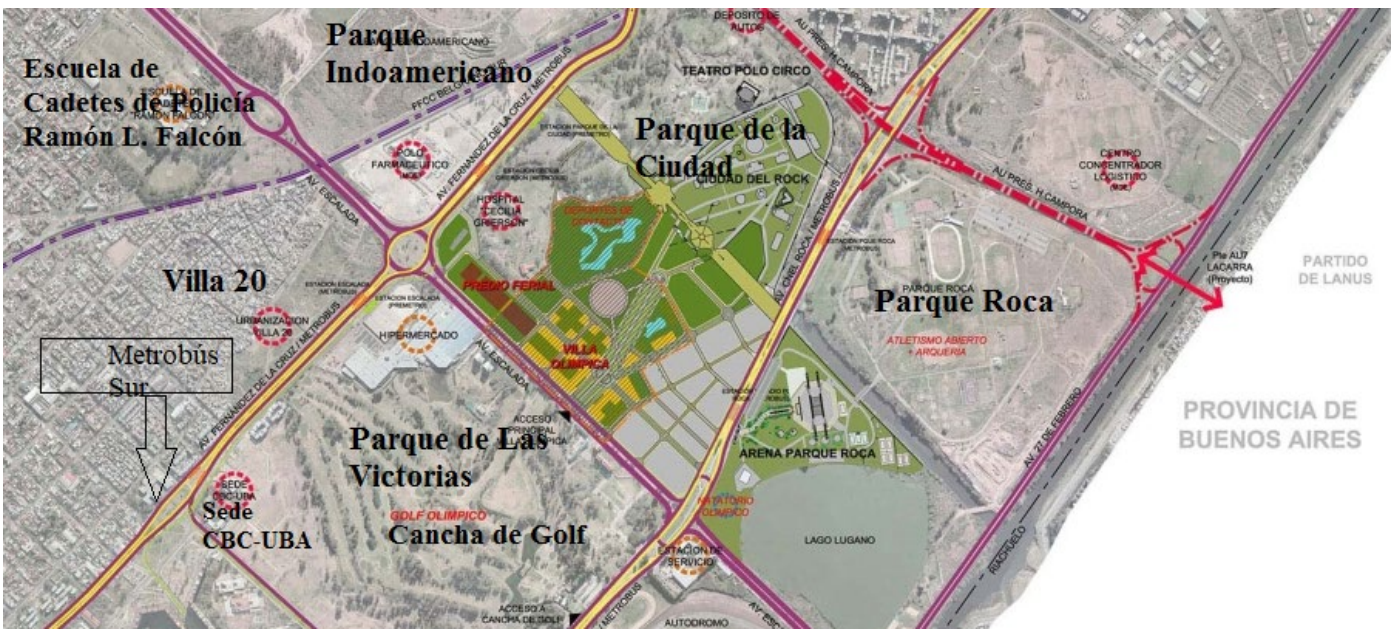

Figura 1. Las barreras urbanas de la Villa 20. Fuente:Elaboración propia en base al mapa de la Dirección General de Estadística y Censos del Ministerio de Hacienda del GCBA. 
En síntesis, el proceso de segregación residencial subsume en la precariedad urbana a una población trabajadora joven, migrante de los países limítrofes, especialmente de origen boliviana. Finalmente, surge la inquietud de analizar cómo dialoga el Estado actual con estas condiciones resultado de un proceso histórico de intervenciones fallidas.

\section{Análisis normativo}

Advenimiento de la democracia (1984-1990): Política de radicación e integración. En la década de 1980 con el retorno del régimen democrático, en forma paralela a la profundización de las políticas de ajuste estructural, ocurrió en la CABA una reconstrucción o repoblamiento de las Villas bajo un laisser faire estatal, aunque sin alcanzar las dimensiones previas a la erradicación. Al mismo tiempo, emergieron la ocupación de edificios y la toma de tierras en el conurbano bonaerense.Los asentamientos informales son producto de la toma de tierras organizada colectivamente que se produjeron desde comienzo de la década de 1980 en las zonas periféricas del Gran Buenos Aires. A diferencia de las Villas, desde el inicio se configuró un tejido urbano regular, amanzanado y parcelado, cuestión que favorece su posterior regularización (Di Virgilio et al., 2010; Rodríguez, 2005; Torres, 2006).. En esta década, se implementó también la primera normativa con un objetivo de radicación de la población villera. En 1984, se sancionó la Ordenanza № 39753 que postuló la necesidad de transformar las villas en barrios e integrar a sus habitantes a la trama sociourbana de la ciudad, estableciéndose así el derecho de la población a permanecer en el territorio ocupado, revirtiendo de esta manera la política desarrollada por el gobierno militar.

En la década de 1990, con la consolidación del neoliberalismo en todo el país y la configuración de un proceso de acumulación económica centrada en los negocios inmobiliarios y en la desposesión de los sectores populares, se sucedió un crecimiento y densificación de las villas de la ciudad. Esto último se debió al desarrollo de un dinámico mercado inmobiliario informal mediante operaciones de compraventa y de alquiler (Cravino, 2014; Motta y Almansi, 2017; Rodríguez, 2005; Torres, 2006). Esta última situación profundizó la segregación residencial y generó un mecanismo de desigualdad al interior de las Villas, cuestión que explica en parte la toma de tierras ocurridas en la CABA desde el año 2010.

En este contexto, se desarrollaron dos tipos de políticas opuestas entre sí. La primera, postuló la necesidad de una política de regularización dominial en consonancia con las recomendaciones de los organismos internacionales y los postulados de De Soto (1987) sobre la posibilidad de mejoramiento espontáneo e individual del hábitat a partir del acceso a la propiedad formal de la vivienda. Esta política supuso una baja o nula inversión del Estado y, en contrapartida, la obtención de recursos a través de la venta de tierras y la posterior recaudación impositiva (Rodríguez, 2005). La segunda, mediante la Ordenanza № 44873/ 1991 se condicionó la regularización dominial a la urbana, matizando los postulados de De Soto, a partir de la afectación de los polígonos de todas las villas de la ciudad al distrito U31 (Distrito de Urbanización determinada) ${ }^{9}$ del CPU. Luego, el Decreto №1531/91 reglamentó la misma Ordenanza, y le asignó a la CMV la realización de los proyectos de urbanización y de subdivisión, en tanto la Secretaria de Planeamiento fue la encargada de procesar y concentrar toda la información.

Además, se promulgaron normativas que permitieron la transferencia de la propiedad de los terrenos fiscales en dominio del gobierno nacional. Los terrenos donde se localiza la Villa 20 se encontraban bajo el dominio de Nación, con la aplicación del Decreto №1001/90, se la declaró innecesaria y se autorizó la venta a sus pobladores (CESBA, 2017; Di Virgilio et al., 2010).

La relación con las organizaciones barriales y sus efectos sociourbanos. La cuestión de la radicación de villas se originó en la década de 1970 en el contexto de la implementación de la política erradicadora llevada a cabo por un gobierno peronista bajo la conducción de López Rega a cargo del Ministerio de Bienestar Social. Esta fue impulsada por el Movimiento Villero Peronista y las Comisiones Vecinales de las villas. Entre sus demandas se encontraban el mejoramiento del hábitat,

\footnotetext{
${ }^{9}$ El Distrito U31 flexibilizó algunas de las disposiciones del Código e introdujo ciertos estándares físicos orientados al mejoramiento del hábitat (Arqueros Mejica, 2016b; Cuenya, 1993; Di Virgilio et al, 2010;).
} 
la transferencia de la propiedad a sus ocupantes y la participación activa de la población en el diseño e implementación (Arqueros Mejica, 2016a). La recuperación de las garantías constitucionales tuvo un impacto en la organización al interior de las Villas. Hacia fines de la década de 1980, la Comisión vecinal de la Villa 20 se había reconstruido de tal manera que integraba el Movimiento de Villas y Barrios Carenciados, cuyo eje de reivindicación era la radicación definitiva de sus barrios (CEBSA, 2017). La demanda referida a la participación se incluyó en la Ley de 1998, que será analizada más adelante. En este sentido, el andamiaje jurídicoadministrativo señalado ocurrió en el marco de una relación de fuerza $\mathrm{y} / \mathrm{o}$ diálogo constante con las organizaciones villeras (CESBA, 2017; Cuenya, 1993).

En la década de 1990, la ejecución del proceso de regularización de las Villas de la ciudad generó resultados limitados. Esto se debió fundamentalmente al predominio de la sanción de normativas específicas para cada caso cuyos resultados dependieron más bien de las relaciones de fuerza entre las instituciones y las organizaciones involucradas en un contexto determinado de consolidación del neoliberalismo en la ciudad. En general, esta última se centró en la provisión de servicios e infraestructura urbana, quedando relegadas las intervenciones referidas a la regularización de las edificaciones y del saneamiento del dominio por la carencia de una flexibilidad normativa (CEBSA, 2017; Di Virgilio et al., 2010). En síntesis, en la CABA desde la transición democrática, pese a los diversos programas aplicados, fueron escasos los avances normativos necesarios para poder llevar a cabo la regularización en situaciones de informalidad urbana (Di Virgilio et al., 2010).

El supuesto avance en la regularización urbana de algunas de las Villas de la ciudad resultó con posterioridad ser deficiente frente a la intensa dinámica demográfica. En la Villa 20, la CMV realizaron 53 viviendas mediante el sistema de autoconstrucción y se llevaron a cabo algunas obras de mejoramiento que resultaron con el tiempo deficientes y obsoletas. Se tendió la red de agua corriente y cloacas en distintos sectores, se asfaltaron algunas calles que se sumaron a las ya asfaltadas en 1987. La Cooperativa 25 de marzo, en las manzanas bajo su dominio, llevó a cabo un reordenamiento parcelario y un mejoramiento habitacional con financiamiento público. Estas políticas de regularización no sólo demoraron en su ejecución si se tiene en cuenta que la primera Ordenanza fue sancionada en el año 1984, sino que resultaron parciales y no alcanzaron la integración sociourbana postulada.

\section{Consolidación del neoliberalismo ¿Plan integral o fragmentación?}

En el año 1998, la legislatura porteña sancionó la Ley №148 (Comisión de Vivienda de la Legislatura Porteña y la Asociación Civil por la Igualdad y la Justicia, s.f.) De Atención prioritaria a la problemática social y habitacional en las Villas y Núcleos habitacionales Transitorios, en sintonía con el artículo 31 de la Constitución de la CABA (1996), que previamente (1994) había cambiado su estatus de municipio a uno de Ciudad Autónoma. Esta Ley dispuso la gestión democrática mediante la creación de una Comisión Coordinadora Participativa. Lo dispuesto por esta Ley cristalizó en parte las demandas de las organizaciones villeras de los años '70 y '80. De este modo, la normativa expresa la relación de fuerza (entre el Estado y la sociedad civil), pero simultáneamente los efectos de ésta última no son inmediatos en el tiempo.

Con posterioridad, se aprobaron leyes, decretos y resoluciones (Rodríguez y Vitale, 2016) que aludían a problemáticas y Villas particulares, ya contempladas en su generalidad en la Ley №148 (Comisión de Vivienda de la Legislatura Porteña y la Asociación Civil por la Igualdad y la Justicia, s.f.). La sanción de la Ley №1770/2005 (Comisión de Vivienda de la Legislatura Porteña y la Asociación Civil por la Igualdad y la Justicia, s.f.) (y de la Ley №2054 de 2006) de la Villa 20 forma parte de esta respuesta fragmentada por parte del Estado, impidiendo así una solución integral a la problemática urbana y habitacional de las Villas de la ciudad.

El paradigma de la regularización dominial en los primeros años del siglo XXI (2005-2010). La Ley №1770 del año 2005 afectó los terrenos de la Villa 20 al Distrito U8-Lugano $\mathrm{V}$ del CPU; encomendó la realización de un Censo en el término de treinta días de promulgada la presente Ley; y definió el polígono Papa Francisco destinado a la construcción de viviendas sociales y de equipamiento comercial, además de establecer la necesidad de la participación de los vecinos en todas las 
etapas del proceso tal como estaba estipulado en la Ley №148 (Comisión de Vivienda de la Legislatura Porteña y la Asociación Civil por la Igualdad y la Justicia, s.f.). El IVC, surgido en el año 2003 en reemplazó de la CMV, fue el encargado de planificar la urbanización de Villas, asentamientos y núcleos habitacionales transitorios.

En el año 2007, con la asunción del Ingeniero Mauricio Macri como jefe de gobierno de la CABA, el diseño institucional de la política habitacional pasó a depender del Ministerio de Desarrollo Económico. Se encomendó a la Corporación Buenos Aires Surdesplazando así al IVC de sus funciones principales- la tarea de la urbanización de las Villas (a través del PROSUR Hábitat), con especial énfasis en la regularización dominial (con intereses de recaudación impositiva) antes que en la reurbanización o construcción de viviendas nuevas; a la Unidad de Gestión de Intervención Social (UGIS) las obras de emergencia a través de las cooperativas y las cuadrillas de los propios vecinos; y la Secretaría de Hábitat e Inclusión Social buscó generar un anclaje territorial a partir de la creación de las Unidades Territoriales de Inclusión Urbana.

Los distintos programas de intervención en las Villas se fragmentaron entre estos distintos organismos, generando una superposición de funciones y atribuciones que atentó contra un enfoque integral a la problemática y produjo incoherencias e ineficiencias en el accionar estatal (Asesoría Tutelar, 2014; CESBA, 2014; Vitale, 2009). Lejos de la retirada del Estado como promueve la ideología neoliberal en términos generales $y$, especialmente, el discurso del PRO asentado en la "no política", se puede observar una presencia estatal con anclaje territorial con un fin político específico.

La relación con las organizaciones barriales y sus efectos sociourbanos. La Ley $\mathrm{N}^{\circ} 1770 / 2005$ se sancionó, luego de fuertes disputas, en conjunto con la Ley $\mathrm{N}^{\circ} 1768$ del Polo Farmacéutico y la Ley N¹769 de construcción de un Hospital General de Agudos en Villa Lugano (En el año 2009 se construyó el Centro de Salud Integral Cecilia Grierson que cuenta con una capacidad de servicios limitada (Asesoría Tutelar, 2014)). Las luchas y resistencias previas $^{10}$ conformaron el escenario de reactualización de la cuestión referida a la reurbanización que tuvo su repercusión institucional. En este contexto, los habitantes de la Villa 20 comenzaron a trabajar en un proyecto de ley de reurbanización propio. Una vez aprobada la Ley de 2005, comenzaron a poblarse las manzanas 28,29 y 30 de la Villa 20, correspondientes al predio Papa Francisco.

En el marco político e institucional descripto, se aprobó la Ley $\mathrm{N}^{\circ} 2054 / 2008$, que declaró la emergencia ambiental, sanitaria y de infraestructura de la Villa 20, promulgando su resolución en 365 días (Motta y Almansi, 2017). Sin embargo, la actuación de la UGIS frente a las situaciones de emergencia fue deficitaria ya que su intervención quedó sujeta a unas limitadas partidas presupuestarias. Asimismo, la Corporación Buenos Aires Sur tampoco logró importantes avances en la Villa 20 ya que sólo informó su responsabilidad en la construcción de un Polideportivo, de 25 viviendas - en el marco acuerdo con la Cooperativa 25 de marzo- y de 33 títulos de propiedad financiados con créditos del IVC en una sola manzana donde habitan más de 300 familias. Debido al carácter "viviendista" de esta política (Coulomb, 2012) no se realizó un mejoramiento habitacional y de la infraestructura barrial, generando así una profundización de la precariedad urbana.

En diciembre del año 2010 ocurrió la toma del Parque Indoamericano, ubicada enfrente de la Villa 20, como respuesta al déficit habitacional estructural de la CABA (y especialmente de la zona sur) y al "agotamiento de un ciclo de crecimiento de las villas" (Cravino, 2014, p.). Este proceso de inquilinación de las villas puso de manifiesto la falta de tierras que inhibe el crecimiento horizontal y promueve la verticalización o el crecimiento en altura ante una densificación veloz (Cravino, 2014; Rodríguez, Rodríguez y Zapata, 2016). El protagonismo de la población migrante de la villa bajo estudio, especialmente de origen boliviana, en estas acciones colectivas muestra la necesidad de profundizar, en futuro

\footnotetext{
10 Los primeros años del siglo XXI, se conformó la Multisectorial Sudoeste con referentes barriales, vecinales y sindicales por la construcción de un Hospital General en Villa Lugano. También el proyecto de construcción del Polo Farmacéutico impulsado por la Cámara de Farmacéuticos Nacional y la Corporación Buenos Aires Sur contó con la resistencia de los vecinos.
} 
abordajes, la relación entre la clase social y la pertenencia no sólo nacional sino étnica.

La toma del Parque Indoamericano con gran impacto mediático puso en escena la problemática habitacional de los sectores populares y trabajadores que habitan las villas de la ciudad. En simultáneo, dejó en evidencia el desacople producido entre el avance legal y la falta o escasa intervención estatal que busque transformar estructuralmente el territorio; es decir, se produjo un distanciamiento entre la ley y su ejecución. En resumen, la reactivación de la cuestión referida al derecho a la ciudad provino de la repercusión de estas acciones colectivas.

El conflicto se desplazó también a la arena judicial (de la ciudad) en tanto derechos constitucionales y legales incumplidos. Entre ellos se pueden nombrar para el caso de la Villa 20: la judicialización de las elecciones de la comisión vecinal (2004) para dar cumplimiento a lo establecido en la Ley №148 (Comisión de Vivienda de la Legislatura Porteña y la Asociación Civil por la Igualdad y la Justicia, s.f.); la judicialización del depósito de autos de la policía (2006) ${ }^{11}$ por los efectos nocivos a la salud de la población causados por contaminación, entre otros (Asesoría Tutelar, 2014; CESBA, 2017).

En este contexto de disputa a nivel judicial, en el año 2013 el Poder Ejecutivo remitió a la Legislatura de la ciudad el proyecto de Ley Plan Maestro para la Comuna $8^{12}$ (Legislatura de la ciudad autónoma de Buenos Aires, 2012). En su versión original, autorizaba la venta a privados (a través de la Corporación Buenos Aires Sur) del predio de la Policía Federal a pesar de que a través de la Ley $\mathrm{N}^{\circ} 2.692 / 2008$ se establecía la devolución de los predios al GCBA para la reurbanización de la Villa 20. Las familias que durante décadas cuidaron los predios de ser usurpados, en febrero de 2014 decidieron ocuparlo ante la amenaza de su posible venta. Con el paso de los meses se fue consolidando el Barrio Papa Francisco que fue desalojado violentamente por orden judicial.

\footnotetext{
11 Este predio tenía una situación dominial compleja. Fue traspasado a la Policía Federal en el año 1981 bajo la última dictadura militar, pero nunca se concretaron los trámites de saneamiento.

12 De la discusión de este proyecto en la legislatura porteña, surgió finalmente la sanción de la Ley N5235/2014 de Promoción de las Actividades de la Producción e Industria Deportiva.
}

Luego de la toma de este predio, se consolidó la Mesa Activa por la Reurbanización del Barrio, conformado por un grupo de referentes de la Villa 20 que contó con el asesoramiento de la Cátedra Libre de Proyecto Social de la FADU. En el año 2015, a un año del desalojo del barrio Papa Francisco y a 10 años de la sanción de la Ley №1770, se desarrolló una movilización al obelisco por la reurbanización de la Villa 20 , disputando y reactualizando nuevamente el contenido de ésta. Así, se logró suplir el proyecto de reurbanización presentado en el año 2015 por el legislador Cristian Ritondo (PRO) que en líneas generales impulsaba “(...) una mera regularización dominial de las viviendas y la colocación de nombres a las calles/pasillos de la villa sin incluir mejoramiento barrial" (Entrevista a un referente del barrio). Además, no respetaba las Leyes №148 y №1770 (Comisión de Vivienda de la Legislatura Porteña y la Asociación Civil por la Igualdad y la Justicia, s.f.) que instaba la participación vecinal.

En síntesis, la intervención estatal a través de sus distintos organismos estuvo principalmente centrada (aunque de manera ineficiente) en la atención de la emergencia y en la regularización dominial, dejando sin ejecutar las leyes de reurbanización. Asimismo, esta política se enmarcó en discursos hostiles hacia las villas y su población por parte de los funcionarios del gobierno de turno. El desalojo violento del Parque Indoamericano y del barrio Papa Francisco estuvo acompañado de discursos xenófobos hacia la población migrante, especialmente de origen boliviano (Cravino, 2014).

\section{El paradigma de la Gestión Social del Hábitat (2016-} 2018). A dos años de los sucesos de la toma del barrio Papa Francisco y a seis años de la toma del Parque Indoamericano, se aprobó la Ley №5705/2016 de Reurbanización, Zonificación e Integración sociourbana de la Villa 20 bajo la nueva gestión del PRO en el Gobierno de la Ciudad con la jefatura de Horacio Rodríguez Larreta.

En la gestión actual del GCBA, se presentó una reestructuración de las competencias de los organismos y áreas ministeriales mediante la sanción de la Ley de Ministerios de la Ciudad (Ley №5460/15). En primer lugar, el IVC recuperó su rol protagónico en los procesos de reurbanización de villas y junto con la Secretaria de 
Integración Social y Urbana quedaron orgánicamente vinculados a la Jefatura de Gabinete.

A partir del año 2017, la Corporación Buenos Aires Sur perdió injerencia en las villas y asentamientos de la ciudad, y el Programa PROSUR Hábitat dejó de funcionar. Respecto a los recursos financieros para costear las obras de reurbanización de las villas bajo intervención estatal, éstas provienen de origen privado, del endeudamiento internacional y de la venta de terrenos y/o inmuebles del GCBA. Para el caso de la reurbanización de la Villa 20 se prevé su financiación a partir de la venta de 20 manzanas del Parque de la ciudad, transferidos a la Corporación Buenos Aires Sur (CEBSA, 2017). A su vez, mediante la Ley №5.541/2016 se autorizó el endeudamiento externo por 160 millones de dólares con organismos financieros internacionales para revitalizar la Comuna 8 frente al desarrollo de los Juegos Olímpicos de la Juventud del año 2018.

Esta estrategia actual de mercantilización y privatización de las tierras públicas, que opera como una forma de desvalorización del capital público (Topalov, 1979), es una tendencia que profundiza la política urbana operada en la década de 1990, periodo en el que se consolidó el neoliberalismo y se instauró un Estado facilitador y promotor del mercado. En los años '90, la privatización de las tierras públicas -en particular la de los ferrocarriles- fue la base del boom de los negocios inmobiliarios. Este rol protagónico del capital privado en la planificación urbana estuvo acompañado por la flexibilización de las normativas de edificación y uso del suelo a través de diversos mecanismos, como las excepciones al CPU (Fernández Wagner, 2006).

\section{La relación actual con las organizaciones barriales y} los efectos sociourbanos. Esta ley se orienta a la integración urbana, habitacional, e introduce la noción de integración socioeconómica atravesada de manera transversal por el respeto a la identidad cultural del barrio (Motta y Almansi, 2017). Esta Ley sigue los lineamientos dispuestos en el Plan urbano Ambiental (Ley $\mathrm{N}^{\circ} 2930 / 2008$ ), que tiene como finalidad combatir las desigualdades de la ciudad a partir del desarrollo de una "ciudad integrada, plural, diversa, saludable y policéntrica". Además, se incluye en un proyecto de revalorización de la Comuna 8 mediante la creación del Distrito del Deporte (y de la Villa olímpica13), el mejoramiento de los espacios verdes y de la conectividad (Audiencia pública Tratamiento del proyecto de integración y transformación para la reurbanización de la Villa 20, 2016; Audiencia pública Créase el distrito "Villa Olímpica" y modificase la zonificación de una serie de predios tendientes al desarrollo de la Comuna N. 08 de la C.A.B.A., 2016).

Cabe remarcar que por integración habitacional se entiende la inclusión de cada vivienda en el sistema de cloacas, de electricidad y agua potable de la ciudad, además de la mejora de las viviendas y la construcción de viviendas nuevas para lo cual el IVC desarrolló un sistema de créditos para cada solución habitacional (Motta y Almansi, 2017). Las familias relocalizadas en las viviendas nuevas del predio Papa Francisco tendrán acceso a un crédito en cuotas en pesos con tasas de $0 \%$ al $4 \%$, cuyo el monto no podrá superar el $20 \%$ del ingreso familiar. También se les reconocerá el valor de la vivienda del titular o propietario (bajo la lógica de la autoconstrucción) que será descontado del monto final. Para aquellos que decidan relocalizarse fuera del barrio, se promoverá el acceso pero con la intervención de las empresas inmobiliarias. La tercera modalidad es el canje para quienes decidan mudarse a otra vivienda dentro del barrio (Ley №5705/2016; Entrevista a referente del IVC, 2018). Por último, para el mejoramiento de la situación habitacional, las familias también contarán con acceso a un crédito. Esta última modalidad es la que predominó (El $72 \%$ de las familias aceptaron).

En relación con la integración socioeconómica es aún incierta la modalidad a implementar, a sabiendas la importante concentración de población desocupada y de

\footnotetext{
13 La Villa Olímpica, un conjunto habitacional para los jóvenes atletas de los Juegos Olímpicos del año 2018, será propuesto con posterioridad a un sector de clase media con capacidad de ahorro - de la Comuna 8 y del resto de las comunas del sur-y de acceso a un crédito (U.V.A) otorgado por el Banco Ciudad. Se desestimó así el proyecto original de destinar un porcentaje de ese complejo a los habitantes más empobrecidos de la Comuna 8 (Audiencia pública Tratamiento del proyecto de integración y transformación para la reurbanización de la Villa 20, 2016; Audiencia pública Créase el distrito "Villa Olímpica" y modificase la zonificación de una serie de predios tendientes al desarrollo de la Comuna № 8 de la C.A.B.A., 2016).
} 
trabajadores en empleos informales e inestables, que trabajan en el mismo barrio y poseen salarios por debajo de la media de la CABA.

Esta Ley introduce la participación barrial, en sintonía con la Ley $\mathrm{N}^{\circ} 148$ (Comisión de Vivienda de la Legislatura Porteña y la Asociación Civil por la Igualdad y la Justicia, s.f.), a partir de la creación de diversas instancias: por un lado se puede nombrar a la Mesa Técnica (MT) compuesta por organizaciones, referentes barriales $y$ especialistas que elaboran las propuestas respecto a la construcción de viviendas nuevas como en relación al mejoramiento habitacional y urbano en el macizo, presentadas luego a discusión en la Mesa de Gestión Participativa (MGP), compuesta por los distintos organismos del GCBA y abierta a una amplia participación vecinal.

Cabe señalar que la organización previa de los vecinos de manera independiente en la Mesa Activa por la Reurbanización de la Villa 20 (que actualmente es un actor de la $\mathrm{MT}$ ), introdujo algunas modificaciones en la Ley y en el proceso previo a su sanción. Por ejemplo: el reemplazo de un proyecto de construcción de viviendas sociales en el predio del Papa Francisco surgido de un concurso convocado por el GCBA y la Sociedad Central de Arquitectos por un diseño más compatible con la realidad del barrio; la inclusión de los inquilinos en el censo realizado por el IVC; la presencia en la Ley de la entrega de la escritura del dominio de la vivienda luego de finalizado el proceso de mejoramiento barrial, la proyección de 1702 viviendas nuevas ante un Estado que proponía la construcción de 1300 unidades, entre otras (Ley №5705/2016; CESBA, 2017).

Se pone de manifiesto una vez más cómo la presión de las organizaciones sociales puede incidir en el plano normativo legal (Zapata y Beluscio, 2018). Teniendo en cuenta el largo camino de disputas entre los distintos organismos del Estado entre sí y con las organizaciones villeras existente entre la sanción de la Ley y la reurbanización concreta, se considera crucial plantear algunos elementos de análisis en el marco de una intervención estatal reciente.

En primer lugar, en el mejoramiento y construcción de las viviendas nuevas en el predio Papa Francisco, el Estado trabaja con empresas privadas licitadas, alentando así a la industria de la construcción. En simultáneo se otorgarán créditos subsidiados a las familias relocalizadas según los motivos dispuestos por Ley. De este modo, ocurre una mixtura de políticas habitacionales en tanto se impulsa un financiamiento de la oferta como de la demanda, estrategia política presente desde los años '90. Según entrevista a un referente del IVC (2018), el diseño de las viviendas sociales fue consensuada en la MT y luego refrendada en la MGP, no obstante pueden surgir problemas respecto a la asignación de las viviendas, ya que ésta no está vinculada con la antigüedad de residencia de los hogares sino por lo dispuesto en la Ley (por ejemplo, por la necesidad de apertura de calles, por la presencia de problemas asociados al hacinamiento, al esponjamiento, y por riesgo de derrumbe, entre otros).

Se subraya la problemática de la asociación públicoprivada -en el marco de un aumento del endeudamiento con organismos internacionalesrespecto al lobby empresario y a los beneficios clientelares del sector político en torno a la obra pública (Fernández Wagner, 2006), además de la configuración de un proceso que genera una privatización de las ganancias y una socialización de los costos o pérdidas (Harvey, 2007; Topalov, 1979).

También se destaca una de las demandas de los vecinos respecto a la simultaneidad de las obras referentes a la construcción de las viviendas nuevas y al mejoramiento urbano y habitacional. Se encuentra como antecedente el Programa Favela Barrio en Rio de Janeiro (Brasil) donde uno de los problemas fue el efecto cascada generado por los atrasos de ejecución originados por diversas causas (CESBA, 2017). Por el momento, no se presentan avances respecto al tendido de la infraestructura en el macizo del barrio, y surgieron un sinnúmero de irregularidades que muestran el temor a la política viviendista:

No se hizo nada respecto a la infraestructura, no se hizo nada, y lo que se hizo se hizo mal. El proceso iba a marchar junto, la construcción de vivienda nueva y la infraestructura en el barrio, en el macizo. Avanzaron más en las viviendas nuevas que es más visible, una vidriera, un paredón frente a la Villa 20. (Entrevista a un referente barrial, junio de 2018) 
La posibilidad de un efecto cascada atentaría contra el objetivo histórico de integración bajo condiciones urbanas con rasgos segregatorios, exacerbados por la fragmentación urbana y la carencia de urbanidad. Por ende, la persistencia de una organización vecinal independiente se percibe como la clave en el control del proceso de reurbanización.

Por último, esta Ley complementa la Ley №1770, pero introdujo algunas modificaciones. Por ejemplo, se incluyó una flexibilidad normativa, revirtiendo en parte la política de los años '90, con la intención de ejecutar la regularización dominial en la Zona 3 que comprende el sector macizo y el consolidado ${ }^{14}$. Esta última política se inserta en un proyecto de revalorización de la Comuna y en un contexto económico vulnerable, por ende surgen las siguientes preguntas disparadoras: ¿Cómo se asegurará la seguridad de la tenencia de la vivienda de la población con empleos informales y precarios? ¿Qué mecanismos debería adoptar el Estado frente a la posibilidad de una presión del mercado inmobiliario (formal y/o informal) sobre esos terrenos? ¿De qué manera se prevé frenar los posibles desplazamientos de la población más empobrecida de la villa ante la existencia de aumentos especulativos de los precios de los alquileres?

\section{Conclusiones}

La política de radicación de Villas emerge con el retorno de la democracia en Argentina cuyo objetivo era la regularización y la integración sociourbana, reconfigurando así el tejido urbano segregado de la CABA.

En el periodo de la globalización neoliberal, desde la sanción de la primera ordenanza en 1984 hasta la

\footnotetext{
${ }^{14}$ Además, se derogó el nombre Lugano $\mathrm{V}$ del Distrito U8 y las normas contenidas. Sobre el Distrito U8 -que forma parte del Código Urbanístico (Ministerio de Desarrollo Urbano de la ciudad de Buenos Aires. Subsecretaria de Planeamiento, s.f.) recientemente aprobado- es interesante recalcar la eliminación del Factor de Ocupación Total (FOT) máximo en la tipología edilicia de las viviendas nuevas a construir. La eliminación del FOT máximo significa prescindir de un valor numérico preestablecido que limite la capacidad constructiva hacia el interior del terreno. En términos generales, el parámetro de la altura permitida para cada manzana es el que realmente incide en la cantidad de superficie máxima a construir.
}

actualidad se puede deducir la persistencia de una intervención estatal que fragmenta y focaliza territorialmente la problemática habitacional de las villas, cuestión que además contradice la ideología neoliberal centrada en el laisser faire.

Se constató, en general, un avance en el plano legal formal que expresó la relación de fuerza entre las organizaciones sociales y el Estado neoliberal, destacándose la influencia de las primeras en la misma letra de la ley. Si bien esto no significó una traducción mecánica y cortoplacista entre la acción colectiva y el contenido de la Ley. Como se analizó, las luchas de los años '70 y '80 tuvieron un impacto a largo plazo, en la sanción de normativas recién promulgadas en los años '90.

Por otra parte, se presentó una dilatación en la promulgación de ciertas leyes. Por ejemplo, la Ley №5705 de reurbanización de la Villa 20 se sancionó luego de 20 años de la sanción de la Ley №148 y tras once años de la Ley №1770 (Comisión de Vivienda de la Legislatura Porteña y la Asociación Civil por la Igualdad y la Justicia, s.f.). En este periodo, como consecuencia del surgimiento de un sistema judicial propio de la CABA tras alcanzar su autonomía, las controversias generadas por los escasos avances en la ejecución de las leyes se desplazaron a la arena judicial en tanto derechos constitucionales incumplidos. Actualmente, esta política de reurbanización se inserta en un proyecto mayor que comprende un aumento de la mercantilización de la tierra pública y avance potencial del mercado (inmobiliario y de las industrias llamadas blandas) promovido por el mismo Estado en una Comuna sujeta a un proceso de revalorización.

Este desacople entre el plano normativo y su ejecución concreta expresa una forma de intervención política específica bajo la globalización neoliberal, en tanto prima un Estado facilitador o creador de las condiciones necesarias para el desarrollo de los negocios inmobiliarios vía la venta de tierras públicas y la construcción de infraestructura, especialmente centrada en las condiciones materiales que hacen a la movilidad urbana (que en la Villa 20 reforzaron la fragmentación).

En síntesis, en la década del '90 predominó el paradigma de la regularización donde la carencia de una flexibilización normativa (o de voluntad política) impidió 
la regularización dominial y edilicia. En cambio, los supuestos avances en la regularización urbana resultaron ser deficientes frente a la intensa dinámica demográfica de las villas. La gestión de Macri se focalizó en el paradigma de la regularización dominial (con cierto interés en la recaudación impositiva) y de la asistencia a las obras de emergencia; en paralelo a la presencia de discursos hostiles hacia las villas y su población migrante. De este modo, estos antecedentes normativos muestran una política que no tuvo efectos reales integradores y que no combatió la segregación urbana (y la fragmentación territorial), sino más bien la exacerbó. Esto debido al reparto de unos pocos títulos de propiedad o a la regularización de unas pocas manzanas en una de las villas más pobladas de la ciudad, predominando así una concepción "viviendista".

Bajo el actual gobierno de Larreta se estableció el paradigma de la gestión social del hábitat conocido como Modelo Medellín, que retoma el eje de la integración de los años 80, pero introduce una dimensión económica y cultural. También se plantea una flexibilidad normativa para lograr la regularización dominial. De este modo, se señalan continuidades estructurales en la política pública así como diferencias respecto a las décadas anteriores.

La dinámica urbana, económica y cultural de la población nacida en Bolivia por su peso específico es un dato a tener en cuenta en este proceso de reurbanización (Diaz,2017) con el fin de combatir las estigmatizaciones, convertidas reiteradamente en estrategia/discurso político. Además, el desarrollo de las obras de vivienda nueva frente a las demoras en el tendido de infraestructura y en la rehabilitación de las viviendas del macizo pueden generar la coexistencia de una morfología urbana y condiciones habitacionales dispares, cuestión que pone en tensión el concepto mismo de segregación residencial.

En suma, este proyecto de regularización dominial y urbana implica un gasto económico adicional de los hogares en la reproducción de sus condiciones de vida que- ante una inserción laboral vulnerable y la ausencia de políticas concretas centradas en garantizar una verdadera integración socioeconómica puede forjar nuevas y futuras controversias, desigualdades y expulsiones. Por último, frente a un proyecto que tiene como finalidad revalorizar la zona sur de la ciudad, cabe preguntarse: ¿De qué manera podrán resistir el avance de la mercantilización del suelo urbano y del mercado inmobiliario (formal y/o informal) en un contexto macroeconómico de ajuste del gasto público y endeudamiento internacional? Esto último comprende una reflexión acerca de las condiciones necesarias para lograr un acceso igualitario al derecho a la ciudad frente a la falta de evidencia respecto a una política que haya concedido prioridad a la generación de una solución integral y estructural al denominado problema de las villas de la ciudad $[\mathbf{B}$

\section{Referencias}

Adaszko, D. (2013). Segregación residencial socioeconómica y desigualdad en la distribución espacial $y$ en el acceso a bienes urbanos fundamentales en la Argentina de comienzos del nuevo milenio (Tesis de doctorado). Universidad de Buenos Aires, Buenos Aires, Argentina. Disponible en http://danadaszko.blogspot.com/2013/.

Amín, S. (2003). Más allá del capitalismo senil. Por un siglo XXI no norteamericano. Buenos Aires: Paidós.

Angelcos, N. y Pérez, M. (2017). De la “desaparición” a la reemergencia: Continuidades y rupturas del movimiento de pobladores en Chile. Latin American Research Review, 52(1), 94-109. http://doi.org/10.25222/larr.39
Arqueros Mejica, S. (2016a) Lecturas políticas de los procesos de institucionalización de urbanizaciones informales: la regularización de la Villa 19. Barrio INTA de la Ciudad de Buenos Aires (1990-2003). En M. C. Rodríguez, M. C. y M.M. Di Virgilio, M.M., (Comp.) Territorio, políticas habitacionales y transformaciones urbanas. Buenos Aires (pp. 239-298). Buenos Aires: Espacio editorial.

Arqueros Mejica, S. (2016b). La cuestión de la radicación de las villas: Una mirada desde las burocracias estatales. Revista Cuadernos de Vivienda y Urbanismo, 9, (17), 28-49. Disponible en revistas.javeriana.edu.co/index.php/cvyu/article/view L16844/13637. 
Asesoría Tutelar/ Ministerio Público Tutelar de la ciudad de Buenos Aires (2014). Procesos de urbanización de villas de la CABA. Los casos de la Villa 19-INTA, Villa 20 y Los Piletones. Disponible en http://mptutelar.gob.ar/sites/default/files/dtn19 urb anizacion en las villas.pdf.

Audiencia pública Créase el distrito "Villa Olímpica" y modificase la zonificación de una serie de predios tendientes al desarrollo de la Comuna № 8 de la C.A.B.A. [Versión taquigráfica]. (1 de noviembre de 2016). Disponible en https://www.fundacionciudad.org.ar/pdf/AudPubl/20 16-NOV-01 VT-VillaOlimpica.pdf.

Audiencia pública Tratamiento del proyecto de integración y transformación para la reurbanización de la Villa 20 [Versión taquigráfica]. (23 de septiembre 2016). Disponible en http://www.buenosaires.gob.ar/sites/gcaba/files/trat amiento del proyecto de integracion y transforma cion para la reurbanizacion de la villa 20 23-0916.pdf.

Brenner, N. y Theodore, N. (2002). Espacios del neoliberalismo: la reestructuración urbana en América del Norte y Europa Occidental. Londres: Blackwell Publishers, 2002.

Borja, J. (2011). Espacio público y derecho a la ciudad. Revista Viento Sur (116), 39-49. Disponible en https://vientosur.info/spip.php?article6732

Castells, M. (1974). La Cuestión Urbana. Buenos Aires: Siglo Veintiuno Editores.

Cea D' Ancona, M.A. (1996). Metodología cuantitativa. Estrategias y técnicas de investigación social. España: Síntesis.

Clichevsky, N. (2000). Informalidad y Segregación urbana en América Latina. Una aproximación. Revista Serie Medio Ambiente y Desarrollo (28), 1-61.

Clichevsky, N. (2003). Pobreza y acceso al suelo urbano. Algunas interrogantes sobre las políticas de regularización en América Latina. Revista Serie Medio Ambiente y Desarrollo (75), 1-84.
Cosacov, N., Di Virgilio, M.M., Gil, A., Gil, M., Guevara, T., Mori, M., ... Vitale, P. (2011). Barrios al sur: Villa Lugano, Villa Riachuelo, Mataderos, Parque Patricios y Villa Soldati a través del tiempo. Buenos Aires: Documentos de trabajo del Instituto de Investigaciones Gino Germani de la Universidad de Buenos Aires, (56), 1-132. Disponible en http://biblioteca.clacso.edu.ar/Argentina/iigguba/20120228035015/dt56.pdf.

Comisión de Vivienda de la Legislatura Porteña y la Asociación Civil por la Igualdad y la Justicia (s/f). Jornada de discusión y debate "Participación, presentación y derechos políticos en las villas de la ciudad. Material de trabajo (compilación de las leyes: №1251, №148, №1777, Reglamentos Villa 20, Reglamentos Piletones, Proyecto de Ley de Regularización de los Comicios en Villas Sentencia de Cámara de 2o Instancia en lo Contencioso, Administrativo, y Tributario de la Ciudad №2. Disponible en https://acij.org.ar/wpcontent/uploads/Compilado normativo1.pdf.

Consejo Económico y Social de la ciudad de Buenos Aires [CESBA] (2017). Acerca de la integración urbanística y social en villas de la ciudad de Buenos Aires. Disponible en http://www.bdigital.cesba.gob.ar/handle/123456789 $\angle 412$.

Constitución de la Ciudad de Buenos Aires (1 de octubre de 1996). Boletín Oficial de la CABA N 47.

Coulomb, R (2012). Las políticas habitacionales de los estados latinoamericanos. Seminario Taller Internacional Teorías sobre la ciudad. Buenos Aires: Universidad Nacional de General Sarmiento.

Cravino, M. C. [Org.] (2014). Derecho a la ciudad y conflictos urbanos. La ocupación del Parque Indoamericano. Buenos Aires: UNGS.

De Mattos, C. (2002). Transformaciones de las ciudades latinoamericanas. ¿lmpactos de la globalización? Revista EURE, 28(85), 1-11. https://doi.org/10.4067/s0250-71612002008500001 
Cuenya, B. (1993) Programa de Radicación e Integración de Villas y Barrios Carenciados de Capital Federal. Buenos Aires: PNUD. Disponible en http://www.ceurconicet.gov.ar/publicaciones.php?cat id=5\&autor id $=13 \&$ anio=all

Davis, M. (2006). Planet of slum. Estados Unidos: Verso.

De Soto, H. (1987). El otro sendero: la revolución informal. Lima: Instituto Libertad y Democracia.

Decreto №1181, 2007. Código de Planeamiento Urbano. Disponible en

http://www.buenosaires.gob.ar/planeamiento/codig o-de-planeamiento-urbano

Diaz, M. (2014). Hábitat popular y mercado laboral durante el proceso de urbanización El Alto-La Paz (1985-2012) (Tesis de doctorado). Universidad de Buenos Aires, Buenos Aires, Argentina.

Diaz, M. (2017). La inserción socioeconómica y territorial de los migrantes aymaras en la ciudad de El Alto, Bolivia. Revista Economía, Sociedad y Territorio, 17(54), 461-489. Disponible en www.redalyc.org/pdf/111/11150592008.pdf

Di Virgilio, M. M, Arqueros Mejica, S. y Guevara, T. (2010). Veinte años no es nada. Procesos de regularización de villas y asentamientos informales en el Área Metropolitana de Buenos Aires. Revista Ciudad y Territorio. Estudios Territoriales, 63(164), 121. Disponible

en http://revistes.ub.edu/index.php/ScriptaNova/article /view/1704

Duhau, E. (2003). División social del espacio metropolitano y movilidad residencial. Revista Papeles de Población, 9(36), 161-210. Disponible en https://www.redalyc.org/pdf/112/11203608.pdf

Duhau, E. (2013). La división social del espacio metropolitano. Una propuesta de análisis. Nueva Sociedad, (243), 9-91.

Fernández Wagner, R. (2006). Elementos para una revisión crítica de las políticas habitacionales en América Latina. Assentamentos informais e Moradia Popular: subsidios para politicas habitacionais mais inclusivas. Brasil: Instituto de Pesquisa Económica Aplicada -IPEA-Ministerio de Planejamento, Orçamento e Gestio.
García Linera, A. (2011). La construcción del estado plurinacional de Bolivia. Revista Con Sciencias Sociales, (4), 12-41. Disponible en www.ucbconocimiento.ucbcba.edu.bo/index.php/RC CS/article/download/927/928.

Groisman, F. y Suárez, A. (2006). Segregación residencial en la Ciudad de Buenos Aires. Revista Población de Buenos Aires, 3(4), 27-37.

Groisman, F. y Suárez. A. (2010). Segregación residencial e inserción laboral en el conurbano bonaerense, Buenos Aires (Argentina). Revista Población de Buenos Aires, 7(11), 7-28.

Harvey, D. (2004). El nuevo imperialismo: Sobre reajustes espacios-temporales y acumulación mediante desposesión. Revista Viento Sur, 1(447), 1-26. Disponible en https://herramienta.com.ar/articulo.php?id=286

Harvey, D. (2007). Breve historia del neoliberalismo. Madrid: Akal ediciones, 2007.

Harvey, D. (2012). Rebel Cities. From the right to the city to the urban revolution. Londres-Nueva York: Verso.

Hidalgo, D. (2017). Desplazados y colvidados?: contradicciones de la satisfacción residencial en Bajos de Mena Puente Alto, Santiago de Chile. Revista INVI, 32 (89), 85-110. https://doi.org/10.4067/s0718 83582017000100085

Instituto de la Vivienda de la ciudad de Buenos Aires (2016). Informe Final Censo 2016 Villa 20. Disponible en

http://www.buenosaires.gob.ar/sites/gcaba/files/info rme censo barrio 20 final 0 .pdf.

Instituto Nacional de Estadística y Censos [INDEC] (2010). Censo Nacional de Población, Hogares y Vivienda (uso REDATAM). Disponible en https://www.indec.gob.ar/bases-dedatos.asp?solapa $=5$.

Jaramillo, S. y Cuervo, L. M. (1993). La urbanización Latinoamericana, Nuevas Perspectivas. Colombia: Escala. 
Jaramillo, S. (2012). Reflexiones sobre la informalidad fundiaria como peculiaridad de los mercados del suelo en las ciudades de América Latina. En: M. C. Cravino (Comp.), Repensando la ciudad informal en América Latina (pp. 149-197). Buenos Aires: Universidad Nacional de General Sarmiento.

Lefebvre, H. (1978). De lo Rural a lo Urbano. Barcelona: Ediciones Península.

Legislatura de la ciudad autónoma de Buenos Aires. (2012). Proyecto de Ley. Plan Maestro Comuna 8. Disponible en https://www.legislatura.gov.ar/_pagedata/menu/ima ges/nkwhouizpb 1502894341.3236.pdf.

Ley $N^{\circ} 770$. BOCBA N 1453 del 31 de mayo de 2002.

Ley $\mathrm{N}^{\circ} 1779$. BOCBA $\mathrm{N}^{\circ} 2281$ del 22 de septiembre de $2005 . \quad$ Disponible en http://www2.cedom.gob.ar/es/legislacion/normas/le yes/ley1779.html

Ley №2054. BOCBA № 2518 del 7 de septiembre de $2006 . \quad$ Disponible en http://www.ciudadyderechos.org.ar/sistemas I.php?i $\underline{d=40 \& i d 2=426 \& i d 3=1349}$

Ley $\mathrm{N}^{\circ} 2980 / 08$. BOBCA $\mathrm{N}^{\circ} 3091$ del 13 de noviembre de 2008. Disponible en http://www.buenosaires.gob.ar/areas/leg tecnica/si n/normapop09. php? id $=123445 \& q u=c \& f t=0 \& c p=\& r l=$ o.

Ley $N^{\circ} 5705$. BOCBA N5048 del 16 de enero de 2017. Disponible en http://www2.cedom.gob.ar/es/legislacion/normas/le yes/ley5705.html

Massey D. y Denton, N. (1998). The dimensions of residential segregation. Social Forces, 67(2), 281-315.

Ministerio de Desarrollo Urbano de la ciudad de Buenos Aires. Subsecretaria de Planeamiento (s.f.). Código Urbanístico (Borrador). Disponible en http://www.buenosaires.gob.ar/desarrollourbano/nu evo-codigo-urbanistico.
Motta, M. y Almansi, F. (2017). Gestión y planificación del proceso-proyecto para el mejoramiento de villas y asentamientos a gran escala. El caso de la Reurbanización de la Villa 20 en la CABA. Medio Ambiente y Urbanización, 86(1), 145-168. Disponible en

https://es.scribd.com/document/382415999/MOTTAJ-M-y-F-ALMANSI-Gestio-n-y-planificacio-n-porproceso-proyecto.

Oszlak, O. y O’Donnell, G. (1981). Estado y políticas estatales en América Latina: hacia una estrategia de investigación. Buenos Aires: CEDES. Disponible en https://ridaa.unq.edu.ar/bitstream/handle/20.500.11 807/307/06R1995v2n4.pdf?sequence=1\&isAllowed=y

Oszlak, O (1991). Merecer la ciudad: los pobres y el derecho al espacio urbano. Buenos Aires: CEDES.

Oszlak, O. (2007). Políticas públicas, democracia y participación ciudadana. Revista Voces del Sur, 1(1), 1-7.

Pradilla Cobos, E. (2010). Teorías y Políticas Urbanas ¿Libre mercado mundial, o construcción regional? Estudos Urbanos e Regionais, 12(2), 9-21. Disponible en http://rbeur.anpur.org.br/rbeur/article/view/294.

Quijano, A. (2000). Colonialidad del poder, eurocentrismo y América Latina. En E. Lander, E. (Comp.), La Colonialidad del saber: Eurocentrismo, y Ciencias Sociales (pp. 1-246). Buenos Aires: CLACSO/UNESCO.

Rodríguez, M. M. (2005). Como en la estrategia del caracol. Ocupaciones de edificios y políticas locales del hábitat en la ciudad de Buenos Aires. Buenos Aires: El Cielo por Asalto.

Rodríguez, M.C., Rodríguez, M. F. y Zapata, M. C. (2016) Nuevas formas de segregación-integración en los márgenes: alquileres formales e informales en la Ciudad de Buenos Aires. En M.C Rodríguez y M.M. Di Virgilio (Comp.), Territorio, políticas habitacionales y transformaciones urbanas (pp. 271-298). Buenos Aires: Espacio editorial. 
Rodríguez, M. F. y Vitale, P. (2016). Dinámicas urbanas y hábitat popular. Vaivenes de una política fallida de integración social y urbanística en la Comuna 1. En M. C. Rodríguez y M. M. DI VIRGILIO (Comp.), Territorio, políticas habitacionales y transformaciones urbanas (pp.207-238). Buenos Aires: Espacio editorial.

Rodríguez, G. (2008). Segregación residencial socioeconómica en la ciudad autónoma de Buenos Aires. Dimensiones y cambios entre 1991 y 2001 Revista Población de Buenos Aires, 5 (8), 7-30.

Rodríguez, G. (2014). Qué es y que no es segregación residencial. Contribuciones para un debate pendiente. Revista bibliográfica de geografía y Ciencias Sociales, 19(1079), 1-23.

Sabatini, F. y Brain, I. (2008). La segregación, los guetos y la integración social urbana: mitos y claves. Revista EURE, 34(103), 5-26. Disponible en https://scielo.conicyt.cl/scielo.php?script=sci arttext \&pid=S0250-71612008000300001.

Sassone, S. y Matossian, B. (2014). Metropolización, migración y desigualdades sociales. Evidencias geográficas sobre la Región Metropolitana de Buenos Aires". En M. M. Di Virgilio, M. M. y M. Perelman (Coord.), Ciudades latinoamericanas. Desigualdad, segregación y tolerancia (pp. 221-252). Buenos Aires: CLACSO.

Schteingart, M. (2001). La división social del espacio. Perfiles Latinoamericanos, (19), 13-31.

Suárez, A.L., Fernández Wagner, R., Groisman, F., Kaztman, R., Bonacina, A., Bril Mascarenhas, T., ... y Groisman, F. (2009). Aportes para el desarrollo humano en la Argentina. Segregación residencial en Argentina. Buenos Aires: PNUD.

Topalov, C. (1979). La urbanización capitalista. México: Edicol.
Torres, H. (2006). El mapa social de Buenos Aires (19401990). Buenos Aires: Ediciones FADU/UBA.

Torres Gutiérrez, F. (2011). El territorio de los desheredados. Asentamientos chabolistas y experiencias recientes de erradicación en Sevilla. Revista Hábitat y Sociedad, (3), 67-90. https://doi.org/10.12795/habitatysociedad.2011.i3.0 $\underline{5}$

Torres Ribeiro, A. [Comp.]. (2004). El rostro urbano de América Latina. Buenos Aires: CLACSO.

Vitale, P. (2009). La ley y la trama: Villas y política pública en la ciudad. Apuntes sobre trayectoria del Programa de Radicación, Integración y Transformación de villas y núcleos habitacionales transitorios. 5o Jornadas de Jóvenes Investigadores del Instituto de Investigaciones Gino Germani. UBA, Buenos Aires, Argentina.

Wacquant, L. (2007). Los condenados de la ciudad. Gueto, periferias y Estado. Buenos Aires: Siglo Veintiuno editores.

Yujnovsky, O. (1984). Claves políticas del problema habitacional argentino 1955-81. Buenos Aires: Grupo Editor Latinoamericano.

Zapata, M. C. (2017). La política habitacional porteña bajo la lupa. Buenos Aires: ed. Teseo.

Zapata, M. C y Beluscio, S. (2018). De la Autopista 3 al Barrio Parque Donado-Holmberg (Buenos Aires, Argentina): Una larga disputa por el espacio urbano. Quid 16. Revista del Área de Estudios Urbanos del IIGG/UBA, 9(1). 60-90, 2018. Disponible en https://publicaciones.sociales.uba.ar/index.php/quid 16/article/download/2887/pdf 18.

Zimmermann, L. (2014). Segregación espacial y políticas públicas. Revista Territorios, (30), 219-224. 